\title{
RELAÇÕES BRASIL-SURINAME: FRONTEIRA, GARIMPO E IMIGRAÇÃO NO SÉCULO XXI
}

\author{
BRAZIL-SURINAME RELATIONS: BORDER, ARTISANAL MINING \\ AND IMMIGRATION IN THE 21ST CENTURY
}

Camilo Pereira Carneiro ${ }^{1}$

http://lattes.cnpq.br/8277725980658558

https://orcid.org/0000-0001-7229-1298

\section{Scharmory da Silva Soares ${ }^{2}$}

http://lattes.cnpq.br/3727711609420656

https://orcid.org/0000-0001-5381-3126

\section{Hana Karoline Ramos Guedes Lichtenthaler ${ }^{3}$ \\ http://lattes.cnpq.br/2958654874399115 \\ https://orcid.org/0000-0002-2847-3518}

Recebido em: 7 de fevereiro de 2020

Aprovado em: 8 de junho de 2020

\begin{abstract}
RESUMO: As relações do Brasil com a República do Suriname são recentes. O país, antiga colônia neerlandesa, alcançou a independência no ano de 1975. Apesar de partilhar uma fronteira com o Brasil em meio à selva Amazônica, há um extremo desconhecimento e uma carência de informações na mídia brasileira e na academia acerca do país, que conta com uma população de cidadãos brasileiros estimada em 40 mil pessoas. A capital, Paramaribo, possui um bairro habitado pela comunidade brasileira (Tourtonne) que é conhecido como Belenzinho e os fluxos entre os dois países contam com um voo semanal entre Belém e a capital surinamesa. Recentemente, novos projetos para a região de fronteira foram anunciados pelo governo brasileiro, prometendo reverter o histórico distanciamento entre Brasília e Paramaribo, e vêm repercutindo entre comunidades locais. Face ao exposto, o presente trabalho traz uma análise das relações Brasil-Suriname e do papel da comunidade brasileira na sociedade surinamesa, tendo como objetivo aferir se as políticas públicas dirigidas pelo Estado brasileiro à fronteira com o Suriname são eficazes no sentido de impulsionar o desenvolvimento local e dinamizar as relações entre Brasília e Paramaribo. Trata-se de uma pesquisa qualitativa, sob a ótica das Relações Internacionais e da Geografia Política, pautada em análise bibliográfica e enriquecida com cartografia elaborada pelos autores.
\end{abstract}

\footnotetext{
${ }^{1}$ Professor visitante do Mestrado em Fronteiras e Direitos Humanos da UFGD; Doutor em Geografia pela UFRGS com período de estágio doutoral na Université Paris I - Panthéon-Sorbonne; Mestre em Geografia pela UFRJ; Licenciado e Bacharel em Geografia pela PUC-Rio; Bacharel em Geografia pela PUC-Rio. pereiracarneiro.camilo@gmail.com.

2 Discente do curso de Bacharelado em Relações Internacionais da Universidade Federal da Grande Dourados (UFGD). E-mail scharmori@gmail.com.

${ }^{3}$ Discente do curso de Bacharelado em Relações Internacionais da Universidade Federal da Grande Dourados (UFGD). E-mail: hanalichtenthaler@yahoo.com.
} 
Palavras-chave: Suriname. Brasileiros. Garimpo. Fronteira. Imigração.

ABSTRACT: Brazil's relations with the Republic of Suriname are recent. The country, a former Dutch colony, gained independence in 1975. Despite Suriname shares a border with Brazil in the middle of the Amazon rainforest, there is an extreme lack of knowledge and a lack of information in the Brazilian media and in the Brazilian academy about the country, which has an estimated population of Brazilian citizens of 40 thousand people. The capital, Paramaribo, has a neighborhood inhabited by the Brazilian community (Tourtonne) also known by the name Belenzinho (in reference to the Brazilian city of Belém, origin of part of the immigrants). The flows between the two countries have a weekly flight that connects Belém to the Surinamese capital. Recently, new projects for the border region were announced by the Brazilian government, promising to reverse the historic distance between Brasília and Paramaribo, and have been reverberating among inhabitants of the region. In the face of this context, the present work presents an analysis of Brazil-Suriname relations and the role of the Brazilian community in Surinamese society. The article aims to verify the effectiveness of the public policies of the Brazilian State for the border with Suriname in promoting local development and in boosting relations between Brasilia and Paramaribo. It is a qualitative research, from the perspective of International Relations and Political Geography, based on bibliographic analysis and enriched with cartography made by authors.

Keywords: Surinam. Brazilians. Artisanal mining. Border. Immigration.

\section{INTRODUÇÃO}

A República do Suriname é o menor país da América do Sul, com $163.821 \mathrm{~km}^{2}$, localizada na costa norte da América do Sul, faz fronteira com a República Cooperativa da Guiana ao oeste, com a Guiana Francesa a leste, com o Brasil ao sul e com o Oceano Atlântico ao norte. Sua população é de aproximadamente 563.402 habitantes (em 2017) e sua capital, Paramaribo, tem uma população de 332 mil habitantes (estimativa de 2019), sendo expressivo o contingente de brasileiros.

No Brasil, a discreta divulgação do Suriname na mídia e a reduzida atenção da academia fazem do país um dos vizinhos mais desconhecidos dos brasileiros. Nesse sentido, o presente estudo busca contemplar uma lacuna existente na literatura em língua portuguesa acerca da formação social e econômica do país, do período colonial aos tempos atuais, buscando explicar a presença da comunidade brasileira no Suriname e caracterizar o processo migratório, intimamente ligado à extração de ouro. O trabalho aborda ainda temas referentes à modernização da Amazônia, analisa dados da economia do Suriname e afere a baixa densidade institucional na fronteira entre os dois países e as políticas públicas dirigidas a esta região.

Inicialmente, no tópico "Suriname: história, população e fronteiras" são analisados aspectos geográficos do Escudo das Guianas, com ênfase no Suriname e em suas características históricas, econômicas e demográficas. Com uma população muito diversificada, o que explica o uso corrente de diferentes idiomas no país, o Suriname foi colonizado pelos Países Baixos, que implantaram uma economia de plantations com base em mão de obra escrava e servil. Embora 
tenha conseguido sua independência política em 1975, o Suriname permanece atrelado à velha estrutura econômica dos tempos de colônia: dependente economicamente da exportação de commodities.

Por sua vez, o tópico "A comunidade brasileira no Suriname" traz uma análise do contingente de imigrantes brasileiros no país, que segundo o Itamaraty varia entre 15 e 30 mil indivíduos, muitos dos quais vivendo em situação irregular. Grande parte dos brasileiros no Suriname migrou em busca de melhores condições de vida, mas acabou sendo obrigada a exercer trabalhos informais. Não raras vezes sendo vítimas do tráfico internacional de pessoas, esses brasileiros acabam por ser explorados em atividades como prostituição e trabalho escravo. Casos comprovados em pesquisas como as realizadas pela Organização Sodireitos, que elaborou a Pesquisa Tri-nacional sobre tráfico de mulheres do Brasil e da República Dominicana para o Suriname, brevemente apresentada no presente artigo.

Na parte final, o tópico "A fronteira Brasil-Suriname: geopolítica e Amazônia" aborda os aspectos da geopolítica da Amazônia, o distanciamento histórico entre Brasília e Paramaribo, as relações comerciais do Suriname e os recentes projetos apresentados pelo governo Bolsonaro para a região de fronteira entre os dois países, que embora tenham sido criados sob a justificativa de garantir maior segurança e modernização a essa região, onde a presença do Estado é rarefeita, sofrem a oposição de comunidades locais. O artigo analisa ainda a precariedade dos meios de transporte e comunicação na fronteira Brasil-Suriname e os obstáculos para o incremento das interações entre os dois países.

Os tópicos descritos acima e a estrutura do texto foram elaborados com vistas a contemplar o objetivo do artigo, que consiste em aferir se as políticas públicas dirigidas pelo Estado brasileiro à fronteira Brasil-Suriname são eficazes, no sentido de potencializar o desenvolvimento regional e o bem-estar das populações locais e potencializar as relações institucionais entre os dois países. O trabalho configura uma pesquisa qualitativa, básica, pautada em análise bibliográfica e documental, sob a ótica das Relações Internacionais e da Geografia Política, enriquecida com cartografia elaborada com o software ArcGIS pelos autores para o artigo.

\section{SURINAME: HISTÓRIA, POPULAÇÃO E FRONTEIRAS}

A Amazônia brasileira é, ainda no século XXI, precariamente conectada com as demais regiões do Brasil. Algumas de suas áreas são acessíveis apenas por via aérea, configurando os pontos mais isolados do território brasileiro. Este é o contexto do Escudo das Guianas, que abrange quatro estados da Amazônia brasileira, além das Guianas e da Venezuela. Uma região escassamente povoada, que dispõe de uma malha rodoviária diminuta, concentrada nas proximidades do litoral atlântico, como mostra o mapa 1 (que foi elaborado pelos autores com o software ArcGIS e bases do site Diva GIS).

Silva e Rückert (2009) ressaltam que o Escudo das Guinas constitui uma formação geológica que possui uma superfície de $1.787 .100 \mathrm{~km}^{2}$ e corresponde a uma das regiões sul-americanas mais desconhecidas pelos brasileiros. Entendimento corroborado por Monteiro (2018), que afirma que dentre os dez Estados com os quais o Brasil compartilha fronteira o Suriname é um dos menos conhecidos pela população brasileira, havendo uma discreta divulgação do país nos meios de comunicação e nos círculos acadêmicos nacionais. 
Mapa 1 - Escudo das Guianas, conexões viárias e fronteira Brasil-Suriname

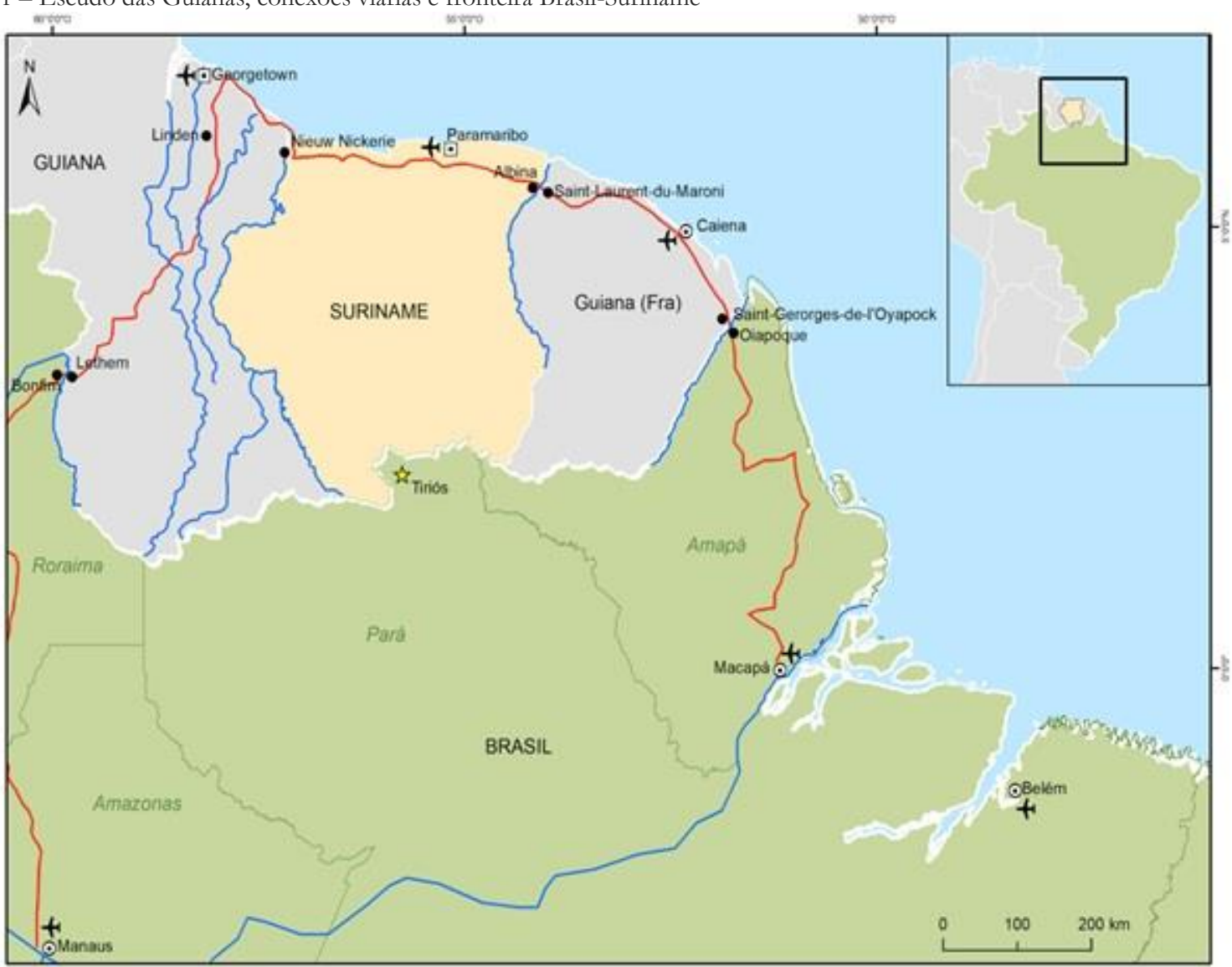

Fonte: Elaborado pelos autores, 2020.

O Suriname é caracterizado por possuir uma população etnicamente diversificada e pela presença de idiomas ${ }^{4}$ distintos daqueles existentes em seus vizinhos sul-americanos. Voltado ao Caribe culturalmente e economicamente, o Suriname possui uma economia rudimentar baseada na exportação de minérios, embora conte ainda com importantes jazidas de petróleo em sua plataforma continental. Suas relações exteriores escassas e seu nível de desenvolvimento são heranças do modelo de colonização e da independência tardia (SILVA; RÜCKERT, 2009).

\subsection{Histórico da colonização do Suriname: aspectos demográficos e econômicos}

Tendo se constituído a partir da colonização promovida pelos Países Baixos, o Suriname originalmente recebeu o nome de Guiana Neerlandesa (Nederlands-Guiana, em neerlandês). Ironicamente, o povoado que deu origem à Guiana Neerlandesa foi criado pelos britânicos em 1651. Com o Tratado de Breda, de 1667, que pôs fim à segunda Guerra Anglo-Neerlandesa, os neerlandeses obtiveram a soberania sobre o território guianês em troca do território de

${ }^{4}$ O neerlandês é a língua oficial do Suriname, mas maioria da população faz uso do sranan (língua franca no país, um idioma crioulo conhecido popularmente como taki taki - corruptela do inglês talk talk). Além disso, as diferentes comunidades étnicas fazem uso das línguas de seus antepassados, como o híndi, o javanês, o mandarim, o inglês, o português, entre outros. 
Nova Amsterdã, então colônia neerlandesa localizada na América do Norte - que com o domínio britânico seria rebatizada de Nova York (CAVLAK, 2016).

A administração da Guiana Neerlandesa ficou a cargo da Companhia de Comércio das Índias Ocidentais (West-Indische Compagnie - WIC) o território passou a ser gerido sob a peculiaridade colonial dos Países Baixos de buscara expansão comercial sem a preocupação em promover o povoamento ou implantar um enclave com seus valores e costumes (CAVLAK, 2015).

A colonização da Guiana Neerlandesa teve como uma de suas principais características a tolerância religiosa, algo que já existia nos Países Baixos. Os calvinistas neerlandeses não forçaram a conversão dos nativos, além disso, a colônia receberia ainda muitos judeus neerlandeses expulsos do Nordeste brasileiro em 1654 (VELTMAN, 2005).

Em relação à exploração econômica da Guiana Neerlandesa havia o interesse na produção de açúcar (commodity muito valorizada no continente europeu no século XVII) e café. A produção agrícola de gêneros tropicais para exportação seria a base da economia colonial ao longo dos séculos seguintes. Esta produção contou inicialmente com a mão de obra de escravos africanos, trazidos entre 1650 e 1808, oriundos, sobretudo, da costa oeste africana. Nesse sentido, cabe destacar que o contingente de escravos africanos levados para a Guiana Neerlandesa era proveniente dos mesmos locais de origem de parte dos escravos que viviam no Brasil. Ou seja, o tráfico negreiro fez com que parcelas da população brasileira e surinamesa possuíssem uma origem étnica comum (MONTEIRO, 2018).

Goldfeld e Franchi (2017) destacam que a Guiana Neerlandesa foi administrada nos séculos XVII e XVIII pela Companhia de Comércio das Índias Ocidentais como uma colônia de plantation, pautada no trabalho escravo, cuja produção era organizada e promovida por uma diminuta população branca (composta por judeus e não judeus). A decadência econômica no final do século XVIII e no início do século XIX resultou na emigração de quase toda população branca não judaica.

Em 1814, após as Guerras Napoleônicas, a Convenção de Londres redefiniu as fronteiras das Guianas entre britânicos (que controlariam as regiões de Essequibo, Demerara e Berbice), neerlandeses (limitados à faixa costeira central) e franceses (que ficariam com uma colônia a leste) (CAVLAK, 2014).

A demografia da Guiana Neerlandesa passou a ser modificada com a abolição da escravidão, em 1863. Com isso, houve um aumento da imigração dos chamados coolies ${ }^{5}$, trabalhadores asiáticos que já vinham chegando à colônia desde a metade do século XIX. De início, foram os chineses (que chegaram entre 1854 e 1874) e posteriormente os indianos (a partir de 1870) e javaneses (que chegaram a partir de 1891). Os novos imigrantes vinham por meio de contratos de trabalho temporários, mas muitos terminaram permanecendo definitivamente (ROSA RIBEIRO, 2002).

Os imigrantes que eram contratados na Índia Britânica trabalhavam nas lavouras de cana e café, onde sofriam com condições de trabalho degradantes. Situação que fez com que em 1916 o governo do Reino Unido proibisse a imigração de indianos para região. No entanto, a imi-

\footnotetext{
${ }^{5}$ De acordo com Santos (2017), o termo coolie é uma generalização usada desde o século XIX e se refere a asiáticos de variadas culturas e origens (chineses, indianos ou pessoas de outras procedências) que trabalharam sob contrato em diversas partes da economia-mundo capitalista, especialmente no século XIX. O termo alude a pessoas com baixa qualificação que tiveram de migrar compulsoriamente e foram submetidas a regimes de trabalho em condições degradantes e violentas em diversas sociedades, como nas regiões escravistas e pós-escravistas da América.
} 
gração de javaneses se manteve, tendo em vista que estes eram provenientes de uma colônia neerlandesa 6 (ROSA RIBEIRO, 2002).

Entre 1838 e 1917 cerca de 240 mil indianos e javaneses foram levados para trabalhar nas Guianas, sendo que um terço deste contingente retornou ao continente asiático (CAVLAK, 2014). A grande diversidade étnica do Suriname fez com que passassem a coexistir no país um grande número de religiões. Este fato moldou a paisagem de cidades como Paramaribo, onde templos de diferentes religiões por vezes estão localizados lado a lado. A cidade chega a abrigar em uma mesma rua uma sinagoga que compartilha um muro com uma mesquita (foto 1).

Foto 1 - Sinagoga ao lado de mesquita em Paramaribo

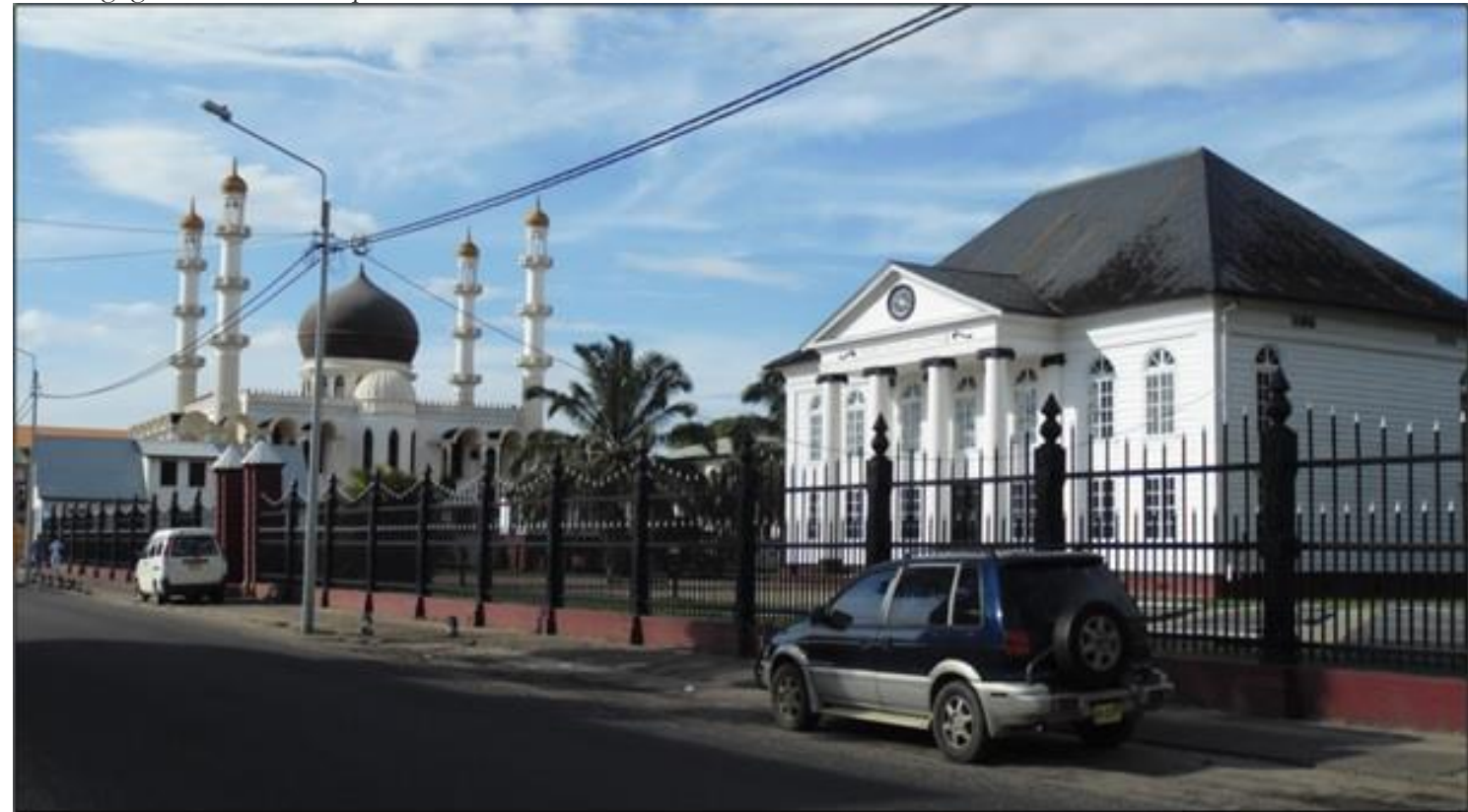

Fonte: Pereira Carneiro, 2013.

Em função da herança colonial e do modelo de exploração do território, que configurava uma grande plantation, a estrutura econômica da Guiana Neerlandesa e, posteriormente, do Suriname baseou-se na produção e exportação de gêneros primários de baixo valor agregado (inicialmente o açúcar e atualmente metais, como o ouro e a bauxita) e na concentração de riqueza.

Esta estrutura socioeconômica explica os altos índices de pobreza e desigualdade que o Suriname apresenta neste início de século XXI. Em 2012, o país figurou na posição de número 105 no ranking de IDH da ONU. Além disso, segundo a FAO (Organização das Nações Unidas para a Alimentação e a Agricultura), entre 15\% e 20\% da população do país sofre de subnutrição (CORREA, 2015). Não obstante a situação de pobreza, o Suriname possui significativas jazidas minerais e de hidrocarbonetos, possuindo assim, um grande potencial energético. Até recentemente esses recursos encontravam-se sob controle de multinacionais da Europa e dos Estados Unidos, o que representa um obstáculo para eventuais políticas de desen-

\footnotetext{
${ }^{6}$ No tocante à colonização neerlandesa da Indonésia, cabe ressaltar que o primeiro contato dos neerlandeses com habitantes de Java ocorreu em 1596. No final do século XVIII, os neerlandeses tinham estendido sua influência ao interior da ilha através da Companhia Neerlandesa das Índias Orientais (Vereenigde Oost-Indische Compagnie - VOC). Com a expansão do domínio neerlandês pelas ilhas vizinhas, a VOC fundou a colônia das Índias Orientais Neerlandesas (1800-1949), que abrangia todo o território da atual Indonésia.
} 
volvimento local (VISENTINI, 2008).

\section{A COMUNIDADE BRASILEIRA NO SURINAME}

Após a independência do Suriname, na década de 1970, teve início a relação diplomática do país com o Brasil, sendo assinados o Tratado de Amizade, Cooperação e Comércio e o Ajuste Complementar ao Acordo Básico de Cooperação Científica e Técnica em 1976. Não obstante, até os dias atuais a fronteira entre os dois países é marcada pela ausência de cidades e rodovias ou vias de acesso.

O isolamento da região da fronteira entre Brasil e Suriname é um problema histórico que chegou a ser contemplado em um projeto do deputado Siqueira Campos, de 1974, no qual era proposta a redivisão territorial da Amazônia Legal. Neste projeto estava prevista a criação do Território Federal do Trombetas, com capital em Monte Alegre, às margens do rio Amazonas. Contudo, a iniciativa não foi levada adiante. Passadas quatro décadas, os projetos governamentais de desenvolvimento voltados à Amazônia, tanto no período ditatorial quanto nos governos democráticos, não alcançaram a região de fronteira do Brasil com o Suriname, que continua sendo uma das mais isoladas da América do Sul.

A falta de interações oficiais relevantes entre os dois países não impediu o advento de um significativo movimento migratório de brasileiros para o Suriname. De acordo com os dados do governo surinamês, os brasileiros configuram o segundo maior grupo de estrangeiros residentes no país. Com um contingente quase igual, embora ligeiramente maior do que o dos chineses, os brasileiros representam aproximadamente 11,65\% do total de imigrantes (contra $11,4 \%$ de chineses). Os dados oficiais apontam um contingente de 5.375 indivíduos, o que faz com que os brasileiros fiquem atrás apenas dos guianenses, principal grupo de imigrantes no Suriname, que somam oficialmente 13.091 indivíduos e representam 28,36\% do total de estrangeiros no país (DATOSMACRO, 2019).

As estimativas, no entanto, não são um consenso entre os diferentes órgãos do Brasil e do Suriname. Segundo o Itamaraty, entre 15 e 30 mil brasileiros residem naquele país, grande parte em condição irregular. Alguns autores chegam a mencionar a cifra de 40 mil imigrantes brasileiros. O fato de os brasileiros entrarem e saírem com frequência do Suriname dificulta o cálculo. A regularização migratória dos brasileiros (muitos dos quais atuam como garimpeiros) vem sendo objeto de contatos políticos de alto nível entre os dois países, que contam com o Grupo de Trabalho sobre Assuntos Migratórios e Consulares, instituído em 2011 (BRASIL, 2018).

A maioria dos imigrantes brasileiros no Suriname chegou ao país com o objetivo de conseguir melhores condições de vida. No entanto, essas pessoas passaram a enfrentar uma situação na qual não contam com uma renda fixa, vivendo em circunstâncias precárias, estando vulneráveis em termos de saúde e direitos civis.

Theije (2005) afirma que a presença de brasileiros no Suriname configura um movimento migratório Sul-Sul que envolve a transnacionalidade e a busca por oportunidades econômicas. Este contingente é oriundo, sobretudo, de áreas rurais do norte do Brasil, sendo composto, em grande parte, por trabalhadores de pouca escolaridade e de classe baixa, que encontram trabalho no garimpo.

No que tange à realidade dos brasileiros no Suriname, Procópio (2007, p. 102) afirma que 
“[...] vitimada pelo Suri-Cartel7 ${ }^{7}$, parte dos imigrantes brasileiros é explorada por organizações criminosas oriundas do Líbano, da Índia e da Nigéria. Esses trabalhadores [...] recebem tratamento de escravos nos garimpos da floresta”.

Já em relação aos brasileiros residentes na capital do Suriname, Theije (2007) recorda que o início da formação da comunidade brasileira em Paramaribo se deu no final do século XX, mais precisamente no período entre 1997 e 1998. A presença dos brasileiros provocou mudanças no cotidiano local, supermercados passaram a vender produtos brasileiros e indivíduos brasileiros passaram a desenvolver atividades comerciais visando atender os garimpeiros. Foram abertos bares, restaurantes, hotéis, lojas de equipamentos de mineração, entre outros. Houve uma concentração maior dos brasileiros no bairro Tourtonne, que passou a ser conhecido como Belenzinho (Klein Belém, em neerlandês), em referência à capital do Pará, estado de origem de grande parte dos imigrantes brasileiros. No Belenzinho se concentram os locais de residência, comércio e negócios (relacionados à compra e venda do ouro) da população brasileira no Suriname.

Cabe ressaltar que os brasileiros que residem em Paramaribo têm a vida e as atividades laborais relacionadas com o garimpo. Aqueles que não exercem a função de garimpeiro atuam no setor de serviços que é sustentado pelo dinheiro do garimpo. No centro de Paramaribo existem diversas casas de compra e venda de ouro (foto 2). Além disso, ao longo das últimas duas décadas, a cultura e os hábitos dos brasileiros garimpeiros passaram a compor o quotidiano de Paramaribo e a influenciar a vida dos habitantes da cidade (THEIJE, 2007).

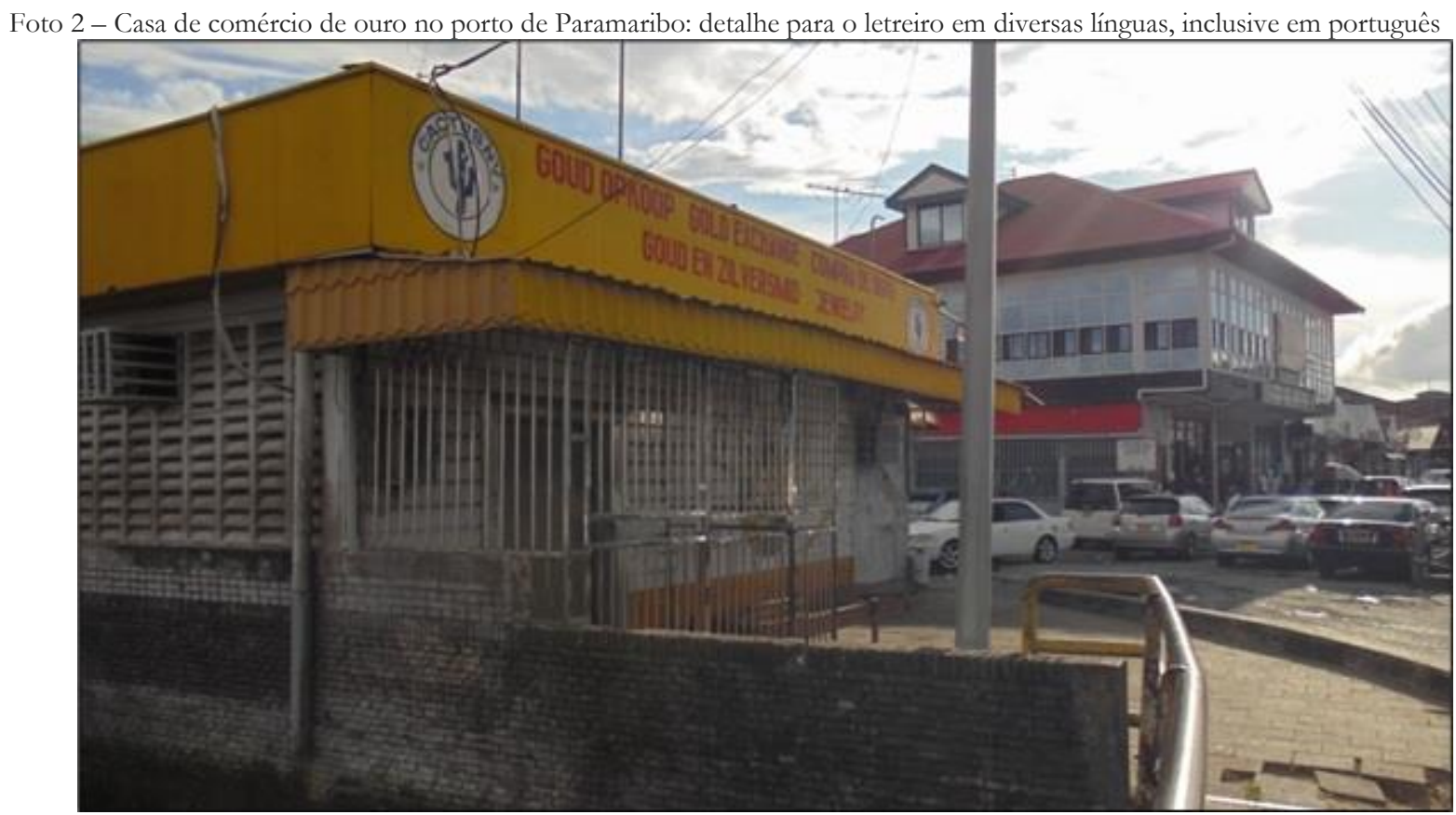

Fonte: Pereira Carneiro, 2013.

No que tange ao garimpo, cabe ressaltar que em virtude deste empregar um grande contingente de homens, configura uma atividade que relega às mulheres as tarefas de cuidar \servir

${ }^{7}$ O Suri-Cartel (Suri Kartel, em neerlandês) foi uma organização criminosa estruturada entre 2000 e 2003 , envolvida no transporte de cocaína da Colômbia para o Suriname e Guiana, de onde a droga seguia para os EUA e Europa. Era liderada pelos traficantes Leonardo Dias de Mendonça e Fernandinho Beira-Mar e chegou a contar com a participação de Dino Bouterse, filho do atual presidente do Suriname, Desi Bouterse (no poder desde 2010). 
os trabalhadores com cuidados domésticos, como lavar, limpar e cozinhar, além do trabalho no circuito da prostituição. O grande número de garimpeiros movimenta o mercado do sexo que é composto por mulheres que vêm do Brasil (OLIVEIRA, 2013). Ao longo do tempo, este mercado vem sendo ampliado para atender a demanda dos garimpeiros. As mulheres são levadas às regiões de garimpo muitas vezes por meio do tráfico de pessoas. Comumente seduzidas por promessas de bons empregos, terminam por sofrer ameaças e violência, sendo envolvidas em uma realidade na qual ficam ainda mais indefesas e expostas (BRASIL, 2011).

As mulheres brasileiras residentes no Suriname que são vítimas do tráfico internacional de pessoas são aliciadas, sobretudo, no Pará e no Maranhão com promessas falsas de trabalho e quando chegam ao país são inseridas à força no circuito da prostituição. Foi o que comprovou a Pesquisa tri-nacional sobre tráfico de mulheres do Brasil e da República Dominicana para o Suriname, realizada pela Organização Sodireitos ${ }^{8}$ e publicada em 2008. No âmbito da referida pesquisa (na qual os nomes das entrevistadas foram substituídos por letras para proteger a identidade das vítimas) foram relatadas experiências de mulheres brasileiras como DI:

Foi convidada a ir para o Suriname a fim de trabalhar num restaurante, mas na verdade foi levada com mais sete meninas para um clube fechado, quando tinha 23 anos. 'Quando cheguei lá, fiquei assustada. Tinha até um micro-ônibus pra levar as meninas. Chegando lá, eu olhei e vi um monte de mulheres num privê. Funciona de dia, para as meninas que querem trabalham pra pagar mais rápido (a dívida). Tem uma que é obrigatório trabalhar. Quando foi à noite, ele (o dono do clube) chamou as meninas no escritório, ele deu as boas-vindas e disse que se fôssemos obedientes poderíamos ser grandes amigas dele. Foi um inferno. Fazia programa até doente pra pagar habitação, comida e limpeza' (SODIREITOS, 2008, p. 69).

Ainda no âmbito da prostituição, a realidade das mulheres no interior do Suriname, em especial nas áreas de garimpo, é marcada por diferentes formas de exploração. Existem diferentes tipos de trabalho sexual, dois envolvendo surinamesas em situações independentes (acampamentos de prostitutas ou moradoras de aldeias próximas de sítios de garimpo), outro que envolve vendedoras e cozinheiras que eventualmente exercem trabalhos sexuais, e o trabalho nos clubes próximos de garimpos, onde prevalece o sistema sexo por crédito, no qual o tráfico de mulheres é materializado (ANTONIUS-SMITS, 1999).

No tocante ao tráfico de mulheres brasileiras para os garimpos no Suriname, cabe destacar a situação da escravidão por dívida. Chegando ao país, as mulheres brasileiras vítimas da exploração sexual são obrigadas a pagar os custos da viagem, da hospedagem, da alimentação e de exames médicos ao dono do garimpo. De acordo com Antonius-Smits (1999), as mulheres permanecem três meses em média à disposição dos garimpeiros para manterem relações sexuais. Ao final desse período o dono do garimpo desconta 10\% dos salários dos garimpeiros e paga um salário pré-estabelecido às vítimas da exploração sexual (as mulheres são obrigadas a aceitar todos os clientes, não podem sair do estabelecimento e têm metas estipuladas no tocante ao número de programas que serão realizados).

\footnotetext{
${ }^{8}$ Criada em 2006, a Sociedade da Defesa dos Direitos Sexuais da Amazônia - Organização Sodireitos-é uma organização civil voltada para a defesa dos direitos sexuais migratórios na Amazônia. Em 2014 a organização implementou o projeto "Diásporas no Enfrentamento ao Tráfico de Pessoas entre o Brasil e o Suriname", realizado entre agosto e dezembro do referido ano, em parceria com o Grupo Mulheres em Movimento, a Universidade Federal do Pará e a Secretaria de Justiça e Direitos Humanos, com o apoio da Secretaria Nacional de Justiça, do Ministério da Justiça e do Escritório das Nações Unidas sobre Drogas e Crime (UNODC).
} 
No interior do Suriname as relações entre o tráfico de pessoas e o garimpo clandestino moldaram um circuito que envolve diferentes atividades ilegais transnacionais que hoje estão interconectadas. Nesse sentido, Nunes Coelho (2011) afirma que no Suriname as redes de prostituição muitas vezes patrocinam os garimpos por meio de empréstimos realizados por cafetões do Pará. Tais redes interligam pessoas no Brasil, no Suriname e nos Países Baixos e promovem ainda o tráfico de mulheres para a prostituição na Europa.

\section{A FRONTEIRA BRASIL-SURINAME: GEOPOLÍTICA E AMAZÔNIA}

Na década de 1990 Becker e Egler (2006) afirmavam que a Amazônia assumia a expressão básica das fronteiras e em função da ausência de organizações sociais capazes de oferecer resistência o governo federal passou a promover a modernização da região. Com a implementação de programas e projetos o valor da terra na Amazônia passou a crescer, resultando também no aumento dos conflitos sociais.

A expansão da pecuária, da mineração e da exploração da madeira resultou na aceleração do desmatamento, os projetos implantados entre as décadas 1970 e 1980 provocaram uma imigração desordenada, bem como a consequente grilagem de terras e o desequilíbrio socioambiental (OLIVEIRA; CARLEIAL, 2013).

As políticas públicas de caráter desenvolvimentista implantadas pelo governo brasileiro na Amazônia abriram fronteiras para o grande capital internacional e nacional, mas por outro lado esgotaram a capacidade do governo de regular a atuação empresarial e negociar com o capital multinacional. A vulnerabilidade do governo na região se revela na incapacidade de controlar os fluxos de pessoas e mercadorias.

A economia da Amazônia brasileira, pautada na exportação de produtos primários, sofre ameaças que vêm, muitas vezes, do outro lado do limite internacional. É o caso da mosca da carambola, presente nos países do Escudo das Guianas (como o Suriname), que pode destruir plantações de frutas de exportação, cuja importância é muito relevante para a economia amazônica (BRASIL, 2019). Nesse sentido, uma das iniciativas recentes do governo brasileiro foi a capacitação de técnicos no Suriname para o combate à mosca da carambola. Um dos poucos exemplos de cooperação entre os dois países.

Cabe destacar que, ainda hoje, são diminutas as relações comerciais formais entre Brasil e Suriname. O quadro é agravado pelo fato de o Suriname ter uma restrita pauta de exportações, na qual o ouro representa $67,3 \%$ do total e outros produtos minerais representam $12 \%$. As principais origens das importações do Suriname são: Estados Unidos (US \$ 410 milhões), Países Baixos (US \$ 186 milhões), China (US \$ 138 milhões), Trinidad e Tobago (US \$ 113 milhões) e Brasil (US \$38,3 milhões). Já os principais destinos das exportações do Suriname são: Suíça (US \$ 1,07 bilhão), Hong Kong (US \$ 658 milhões), Bélgica/Luxemburgo (US \$ 345 milhões), Guiana (US \$ 114 milhões) e Emirados Árabes Unidos (US \$ 106 milhões) (OEC, 2017). A tabela 1 reúne os principais países de origem e de destino dos produtos exportados e importados pelo Suriname. 
Tabela 1 - Principais parceiros comerciais do Suriname

\begin{tabular}{|l|l|l|l|}
\hline \multicolumn{2}{|c|}{ Origem das importações } & \multicolumn{2}{c|}{ Destino das exportações } \\
\hline $1^{\circ}$ Estados Unidos & $30 \%$ & $1^{\circ}$ Suíça & $40 \%$ \\
\hline $2^{\circ}$ Países Baixos & $14 \%$ & $2^{\circ}$ Hong Kong & $25 \%$ \\
\hline $3^{\circ}$ China & $10 \%$ & $3^{\circ}$ Bélgica/Luxemburgo & $13 \%$ \\
\hline $4^{\circ}$ Trinidad e Tobago & $8,2 \%$ & $4^{\circ}$ Guiana & $4,2 \%$ \\
\hline $5^{\circ}$ Brasil & $2,8 \%$ & $5^{\circ}$ Emirados Árabes Unidos & $4 \%$ \\
\hline
\end{tabular}

Fonte: OEC, 2017.

Recentemente, o governo federal do Brasil manifestou interesse em reverter o distanciamento histórico entre Brasília e Paramaribo. Em 2019, o governo Bolsonaro anunciou a intenção de promover projetos na região da fronteira Brasil-Suriname. Entre os projetos estão uma ponte no Rio Amazonas, no município de Óbidos, uma hidrelétrica em Oriximiná e o prolongamento da BR-163 até a divisa internacional dos dois países. Todas essas iniciativas estão dentro do Projeto Barão do Rio Branco, ligado ao Programa Calha Norte (BRAGANÇA, 2019).

Cabe destacar que por trás do Projeto Barão do Rio Branco estão interesses de mineradoras multinacionais ${ }^{9}$. Nesse sentido, o estado do Pará já vem sofrendo os impactos de grandes projetos de mineração em áreas de quilombos e terras indígenas. Um exemplo é a atuação da mineradora canadense Belo Sun, cuja presença no Pará tem um histórico marcado por conflitos entre os interesses da empresa com os dos moradores da região e com a preservação do meio ambiente (REUTERS, 2019).

Em resposta à ameaça representada pelo projeto, a Articulação dos Povos e Organizações Indígenas do Amapá e Norte do Pará (APOIANP) e comunidades quilombolas que terão seus territórios diretamente impactados se manifestaram em notas públicas contra o Projeto Barão do Rio Branco (CPISP, 2019).

Não obstante a resistência de povos tradicionais, o Projeto Barão do Rio Branco vai ao encontro dos interesses dos militares brasileiros, que defendem o aumento da presença humana como forma de dirimir as ameaças e a cobiça internacional pela região. Nesse sentido, é importante recordar que na década de 1970 o governo brasileiro incentivou a parceria entre empresas multinacionais e brasileiras na região da fronteira Brasil-Suriname - Projeto Trombetas. Naquela altura as reservas de bauxita da área do projeto eram estimadas em 620.000 toneladas (OLIVEIRA; BRUM, 2018).

Corroborando o histórico entendimento dos militares brasileiros de "integrar para não entregar" (lema criado na década de 1960 no governo do general Castelo Branco)e resgatando a política estratégica de integração nacional ${ }^{10}$ do regime militar (1964-1985), que fora influenciada pelos pensamentos de Golbery do Couto e Silva e Carlos de Meira Mattos, em janeiro de 2020 o governo brasileiro criou o Conselho da Amazônia, coordenado pelo vice-presidente da República.

\footnotetext{
${ }^{9}$ Em relação ao incentivo do governo brasileiro aos projetos de mineração na região da fronteira Brasil-Suriname, no ano de 2009 uma missão multidisciplinar, organizada pela ABC/Ministério das Relações Exteriores viajou a Paramaribo a fim de elaborar projetos de cooperação técnica a serem executados por instituições dos dois países. Nesse sentido, o Grupo de Trabalho (GT) Geologia e Mineração, composto por técnicos da Companhia de Pesquisa de Recursos Minerais (CPRM) e representantes do Serviço Geológico e Mineiro do Suriname (Geologishe Mijnbouwkundige Dienst - GMD) elaborou a proposta do Projeto Mapeamento Geológico e da Geodiversidade na Fronteira Brasil-Suriname (CPRM, 2020).

${ }^{10}$ Vasconcelos (2016) recorda que durante a ditadura cívico-militar (1964-1985), amparados em princípios geopolíticos de segurança nacional e desenvolvimento, os militares defendiam uma política de integração nacional da Amazônia ao ecúmeno nacional. Nesse sentido, foi criado o Programa de Integração Nacional (PIN), em 1970, tendo como principal objetivo a integração física do território brasileiro por meio da construção de rodovias.
} 
Com vistas a integrar uma área considerada "desértica" pelo governo Bolsonaro, promover projetos de mineração e facilitar o escoamento da soja produzida na região Centro-Oeste, as iniciativas anunciadas para o noroeste paraense têm como obstáculo a presença do maior bloco de áreas protegidas do Brasil. São23 áreas, que correspondem a 2 milhões de hectares de floresta equatorial distribuídos em unidades de conservação, terras indígenas e territórios quilombolas.

Ainda no que tange aos projetos governamentais, Lima (2017) recorda que, historicamente, projetos de mineração no Escudo das Guianas têm esbarrado nas dificuldades existentes na região ligadas à dinâmica de segurança. Entre os fatores, cabe destacar o grande fluxo de brasileiros (muitos ligados ao garimpo), a mineração irregular e os problemas decorrentes (armas, drogas, prostituição), a falta de conexão rodoviária na fronteira, os litígios fronteiriços e a influência de potências externas nas Guianas.

Atualmente, a única presença do Estado na região de fronteira do Brasil com o Suriname é o $1^{\circ}$ Pelotão Especial de Fronteira (PEF) (foto 3), onde estão alojados 50 militares e suas famílias. $\mathrm{O} 1^{\circ} \mathrm{PEF}$ está localizado no Parque do Tumucumaque e só é acessado por via aérea, uma vez que a região não possui rios ou estradas de acesso a outras partes do Brasil. A base está a $10 \mathrm{~km}$ do limite internacional e a $940 \mathrm{~km}$ de Belém (BRASIL, 2017).

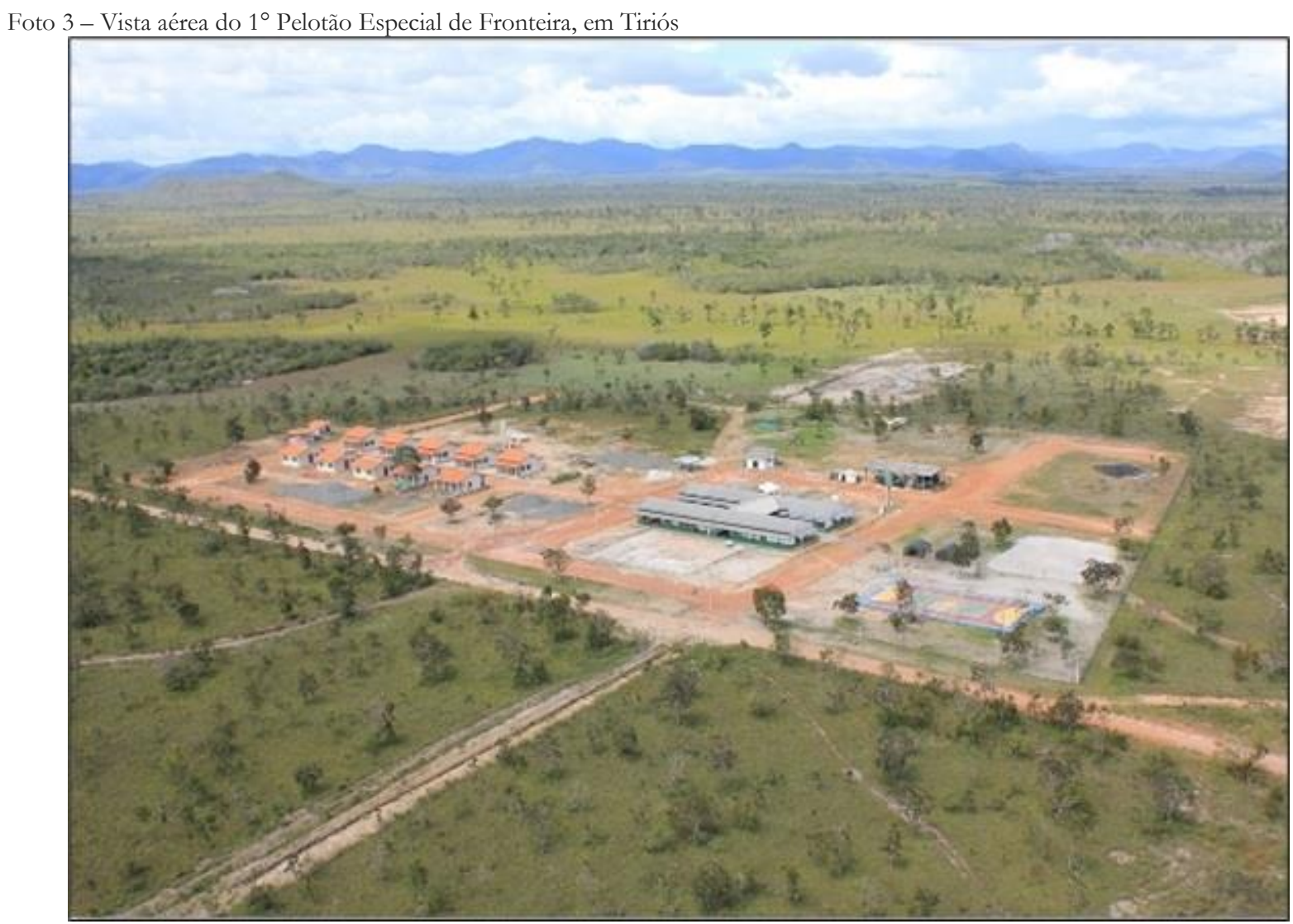

Fonte: Brasil, 2017.

Os Pelotões Especiais de Fronteira, como o de Tiriós, foram criados com o Programa Calha Norte, iniciado em 1985, que promoveu a instalação de unidades militares do Exército Brasileiro no meio da selva amazônica, nas proximidades do limite internacional terrestre do país (FAGUNDES; PEREIRA CARNEIRO, 2017). 
Não obstante os esforços do governo federal, a precária infraestrutura de transportes e comunicações configura um desafio para o aprofundamento das interações entre Brasil e Suriname. No que tange à conexão de transporte entre os dois países, a diminuta oferta de voos e o alto custo dos mesmos configuram um grande obstáculo para as interações entre os dois países. O voo comercial de Belém para Paramaribo, que tem duração de uma hora e cinquenta e cinco minutos, custava em fevereiro de 2020 (bilhete de ida-e-volta) aproximadamente $\mathrm{R} \$$ 1.400,00, sendo oferecido somente pela empresa aérea Gol e apenas nos domingos (GOL, 2020).

É importante ressaltar que a melhoria das infraestruturas disponibilizadas poderia resultar no surgimento de arranjos produtivos localizados. Contudo, de acordo com Oliveira e Brum (2018), na maioria dos casos, a maior disponibilidade de infraestrutura não significa necessariamente que isso irá ocorrer, sendo apenas um primeiro passo naquela direção. No entender dos autores nenhum arranjo produtivo será criado sem que existam outras condições e atividades de suporte necessárias para estabelecer uma cadeia de atividades produtivas centrais e complementares.

\section{CONCLUSÃo}

A relação Brasil-Suriname é marcada pela posição desses países na economia-mundo capitalista. Países periféricos no sistema internacional que compartilham uma fronteira desprovida de acesso por via terrestre e que é escassamente povoada, reflexo das interações diminutas entre os dois países.

Não obstante a escassez populacional, a precariedade de infraestruturas de transporte e a diminuta interação comercial, em função de abrigar uma relevante população de origem brasileira o Suriname deveria ser tratado como um país importante no âmbito da política externa brasileira, no entanto, as escassas conexões formais em termos de comércio regular e transporte denotam a pouca atenção destinada à Paramaribo por Brasília ao longo da história.

Nos últimos anos, a região de fronteira do Brasil com o Suriname passou a ser contemplada em projetos de exploração mineral que envolvem o grande capital internacional e mineradoras multinacionais. Iniciativas que são, ao mesmo tempo, defendidas pelos militares brasileiros, preocupados com a defesa do território nacional, e combatidas por comunidades locais, em especial povos indígenas e quilombolas, que terão seus territórios impactados.

A zona de fronteira entre os dois países continua marcada pela ausência de políticas públicas de desenvolvimento, por iniciativas unilaterais implementadas pelas autoridades brasileiras (Programa Calha Norte e Projeto Barão do Rio Branco) e pela falta de participação das comunidades locais nas decisões governamentais referentes à região, elementos que compõem o quadro da ocupação regional que historicamente vem resultando em intensos conflitos sociais e ecológicos.

Ao longo do tempo, as políticas públicas dirigidas pelo Estado brasileiro à fronteira com o Suriname têm sido elaboradas sem a participação das comunidades locais - caso das iniciativas propostas recentemente pelo governo brasileiro- e não têm abrangido nada além de investimentos em infraestrutura econômica. Tais políticas não contemplam a garantia de acesso a direitos pela população brasileira residente no Suriname (sobretudo os indivíduos vítimas do tráfico de pessoas), tampouco fornecem alternativas de emprego e renda à população de baixa escolaridade da região de fronteira e de grandes centros da Amazônia brasileira. Quadro que 
faz com que a emigração continue sendo percebida por muitos paraenses, maranhenses, amazonenses e amapaenses como alternativa à situação de pobreza e à falta de perspectiva que aflige a maioria da população brasileira e da Amazônia.

\section{REFERÊNCIAS}

ANTONIUS-SMITS, Christel C. F. et al. Gold and Commercial Sex: Exploring the Link between Small-scale Gold Mining and Commercial Sex in the Rainforest of Suriname. In: KEMPADOO, Kamala (ed.). Sun, Sex and Gold: Tourism and Sex Work in the Caribbean. Oxford: Rowman \&Littlefield, 1999. Cap. 11. p. 237-262.

BECKER, Bertha; EGLER, Claudio. Brasil uma nova potência regional na economiamundo (6a edição). Rio de Janeiro: Bertrand Brasil, 2010.

BRAGANÇA, Daniele. Governo quer criar hidrelétrica e abrir estradas em uma das regiões mais preservadas da Amazônia. In:((o))eco. 12 fev. 2019. Disponível em: https://www.oeco.org.br/noticias/governo-quer-criar-hidreletrica-e-abrir-estradas-em-umadas-regioes-mais-preservada-da-amazonia/. Acesso em: 14 nov. 2019.

BRASIL. Laboratório de Demografia e Estudos Populacionais. Tráfico sexual na Amazônia: "um pacto silencioso de reprovação moral e aceitação prática". 2011. Disponível em: https://www.ufjf.br/ladem/2011/08/18/trafico-sexual-na-amazonia-\%E2\%80\%9Cum-pac to-silencioso-de-reprovacao-moral-e-aceitacao-pratica $\%$ E2\%80\%9D/. Acesso em: 03 mai. 2020.

BRASIL. Ministério da Defesa. Comando Militar no Norte: Transporte de equipamento para hidrelétrica. Publicado em: 15 jun. 2015. Disponível em: http://www.eb.mil.br. Acesso em: 14 nov. 2019.

BRASIL. Exército Brasileiro. 10 Pelotão Especial de Fronteira: militares e índios forma amálgama do povo brasileiro, na defesa do país. 26 out. 2017. Disponível em: http://www.eb. mil.br/web/noticias/noticiario-do-exercito/-/asset_publisher/MjaG93KcunQI/content/1pelotao-especial-de-fronteira-militares-e-indios-formam-amalgama-do-povo-brasileiro-na-defesa-do-pais-. Acesso em: 03 fev. 2020.

BRASIL. Ministério das Relações Exteriores. República do Suriname. Publicado em: 14 dez. 2018. Disponível em: http://www.itamaraty.gov.br/pt-BR/ficha-pais/6479-republica-do-suriname. Acesso em: 05 fev. 2020.

BRASIL. Ministério da Agricultura, Pecuária e Abastecimento. Mapa capacita técnicos do Suriname no combate à mosca da carambola. 31 dez. 2019. Disponível em: http://www.agricultura.gov.br/noticias/mapa-participa-de-acoes-de-capacitacao-de-combate-a-mosca-da-carambola-no-suriname. Acesso em: 14 nov. 2019.

CAVLAK, Iuri. Aspectos do desenvolvimento político e econômico da Guyana. In: Revista Política e Planejamento Regional. V. 1, n.1, jul./dez. 2014, p. 234-256.

CAVLAK, Iuri. A Holanda e a América do Sul: A Formação do Suriname. In: Intellector, Rio de Janeiro, v. XII, n. 23, jul./dez. 2015.

CAVLAK, Iuri. O Golpe Militar no Suriname e a Geopolítica no Platô das Guianas. Geopolítica, Natal, v. 1, n. 7, jun. 2016,p.133-151.

CORREA, Paulo Gustavo Pellegrino. Suriname: Um país de costas para a América do Sul. Bauru: Ciência e Geográfica, v. 19, n. 1, dez. 2015.

CPISP. Comissão Pró-Índio. Organizações Indígenas repudiam projetos do governo Bolso- 
naro para o Norte do Pará e Amapá. Disponível em: http://cpisp.org.br/organizacoes-indigenas-repudiam-projetos-governo-bolsonaro-para-o-norte-para-e-amapa/.Acesso em: 04 mai. 2020.

CPRM. Companhia de Pesquisa de Recursos Minerais. Cooperação Brasil - Suriname. Disponível em: http://www.cprm.gov.br/publique/Sobre/Assuntos-Internacionais/Coopera cao-Brasil---Suriname-3915.html. Acesso em: 04 mai. 2020.

DATOSMACRO. Surinam - Inmigración 2019. Disponível em: https:/ / datosmacro.expansion.com/demografia/migracion/inmigracion/surinam?anio=2019\#geo0. Acesso em: 29 abr. 2020.

FAGUNDES, Flávia C. R.; PEREIRA CARNEIRO, Camilo. As políticas de segurança e defesa para as fronteiras no contexto amazônico: uma análise do ponto de vista das políticas públicas. In: COSTA, Jodival Maurício da. Amazônia: Olhares sobre o território e a região. Rio de Janeiro: Autografia, 2017, p. 425-446.

GOL. Passagem Belém-Paramaribo. Disponível em: voegol.com.br. Acesso em: 05 fev. 2020.

GOLDFELD, Monique Sochaczewski; FRANCHI, Tassio. O Brasil e a sua fronteira com o Islã: O caso do Suriname. Monções: Revista de Relações Internacionais da UFGD, Dourados, v. 6, n. 12, p.134-153, jul. 2017.

LIMA, Suely Aparecida de. Integração e relações bilaterais assimétricas: Brasil-Guyanae Brasil-Suriname. Dissertação (Mestrado) - PPG em Sociedade e Fronteiras. Centro de Ciências Humanas, Universidade Federal de Roraima. Boa Vista: UFRR, 2017, 298 p.

MONTEIRO, Julio Cesar Neves. Suriname: história, literatura e questões de tradução. Revista da Anpoll, Florianópolis, v. 1, n. 44, jan./abr.2018, p.100-110.

NUNES COELHO, Maria Célia. Prostituição financia garimpos no Suriname. Publicado em 01 nov. 2011. Disponível em: https://oglobo.globo.com/politica/prostituicao-financiagarimpos-no-suriname-3074793. Acesso em: 03 maio 2020.

OEC. The Observatory of Economic Complexity. Suriname. Disponível em: https://oec.world/en/profile/country/sur/.Acesso em: 7 fev. 2020.

OLIVEIRA, Rafael da Silva de. Mobilidades transgressoras, geográficas ignoradas: itinerários e emaranhamentos envolvendo territorialidades de garimpeiros no Suriname. Tese (Doutorado) - Curso de Programa de Pós-Graduação em Geografia Humana da Universidade de São Paulo. São Paulo: USP, 2013, 401 p.

OLIVEIRA, Robson Quintino de; CARLEIAL, Liana Maria da Frota. Desenvolvimento amazônico: uma discussão das políticas públicas no Estado brasileiro. In: Revista Eletrônica da Faculdade de Alta Floresta, v. 2, n. 1 (2013). Disponível em: http://faflor.com.br/revistas/refaf/index.php/refaf/article/view/90/html. Acesso em: 4 dez. 2019.

OLIVEIRA, Tito Carlos M.; BRUM, Adriana. Desenvolvimento para além das fronteiras: diálogos sobre aspectos sociais, culturais e regionais. Curitiba: Appris, 2018, p. 11-41.

PEREIRA CARNEIRO, Camilo. Trabalho de campo realizado no Escudo das Guianas em dez. 2013. Paramaribo, 4 dez. 2013.

PIRES, Cintia Rafaela. Guiana e Suriname: A inserção de "outra" América do Sul nos processos de integração regional (2000-2013). TCC(Graduação). Curso de Relações Internacionais e Integração da Universidade Federal da Integração Latino Americana. Foz do Iguaçu: UNILA, 2014, 74 p.

PROCÓPIO, Argemiro. A Amazônia Caribenha. In: Rev. Bras. Polít. Int. V. 50, n. 2, 2007, 
p. 97-117.

REUTERS. Belo Sun vê vitória judicial sobre mina no Pará, mas ainda aguarda decisão final. Disponível em: https://economia.uol.com.br/noticias/reuters/2019/07/12/belo-sun-ve-vitoria-judicial-sobre-mina-no-para-mas-ainda-aguarda-decisao-final.htm. Acesso em: 04 mai. 2020.

ROSA RIBEIRO, Fernando. A construção da nação (pós-)colonial: África do Sul e Suriname, 1933-1948. Estudos Afro-Asiáticos, v. 24, n.3, 2002, p. 483-512.

SANTOS, Marco Aurélio dos. Migrações e trabalho sob contrato no século XIX. In: História (São Paulo), Franca, v. 36, 2017.

SILVA, G. V.; RÜCKERT, A. A.. Território e Poder no Planalto das Guianas. In: Anais do $7^{\circ}$ Colóquio de Transformações Territoriais. Desenvolvimento, Integração Regional e Território -Marcos conceituais e de integração. Curitiba: Editora Esplendor, 2009.

SODIREITOS. Pesquisa tri-nacional sobre tráfico de mulheres do Brasil e da República Dominicana para o Suriname: Uma intervenção em rede. Belém: Sodireitos, 2008, 200 p. Disponível em: https://www.justica.gov.br/sua-protecao/trafico-de-pessoas/publicacoes/anexos-pesquisas/2008pesquisa_trinacional.pdf. Acesso em: 01 fev. 2020.

THEIJE, Marjo de. Migrantes brasileiros e a construção de religião popular em Paramaribo, Suriname. In: Numen, Juiz de Fora, v. 8, n. 2, jul. 2005, p. 105-113.

THEIJE, Marjo de. Insegurança próspera: As vidas dos migrantes brasileiros no Suriname. In: Anthropológicas, ano 11, v. 18, n. 1, 2007, p. 71-93.

VASCONCELOS, Gerauly Duarte. A geopolítica dos governos militares brasileiros: a construção das rodovias 174 e 401 no extremo norte da Amazônia (1967 - 1977). Monografia. Curso de História. Universidade Federal de Roraima. Boa Vista: UFRR, 2017, 82 p. VELTMAN, Henrique. Os hebraicos na Amazônia. Rio de Janeiro: Expressão e Cultura, 2005.

VISENTINI, Paulo Fagundes. Guiana e Suriname: uma outra América do Sul. In: Anais da II Conferência Nacional de Política Externa e Política Internacional. Seminário América do Sul. Brasília: Fundação Alexandre de Gusmão, 2008. 